\title{
Manejo de tejidos blandos para preservación de rebordes: Reporte de un caso
}

\section{Juan Francisco Ceccarelli Calle ${ }^{1}$ Miguel Sebastián Delgado Bravo²}

Residente en Periodoncia e Implantes dentales. 2Docente del Departamento Académico de Clínica Estomatológica.

Facultad de Estomatología. Universidad Peruana Cayetano Heredia.

\section{Correspondencia}

Juan Francisco Ceccarelli Calle

Jr. Alfonso Ugarte 366 - Lima 31, Perú

Teléfono: (01)945119290 / 990909434

Recibido : 15 de diciembre de 2009

Aceptado : 13 de abril de 2010
Ceccarelli-Calle JF. Delgado-Bravo M. Manejo de tejidos blandos para preservación de rebordes: Reporte de un caso. Rev Estomatol Herediana. 2010; 20(2):85-89.

\section{RESUMEN}

La pérdida de dientes conlleva a la alteración de los rebordes óseos residuales afectando la estética y función del área. El injerto gingival libre y la exodoncia atraumática son procedimientos conservadores que favorecen la cicatrización, la estética y el mantenimiento de los tejidos, facilitando así su manejo durante la terapia rehabilitadora. Se presenta un reporte de caso de un incisivo lateral izquierdo superior al cual se le realizó una exodoncia atraumática y la posterior colocación de un injerto gingival libre.

Palabras clave: TRASPLANTE AUTÓLOGO / GINGIVOPLASTÍA / EXTRACCIÓN DENTAL / PROCESO ALVEOLAR / CICATRIZACIÓN DE HERIDAS.

Soft tissue management for ridge preservation: A case report ABSTRACT

Tooth loss leads to the alteration of the residual bony ridge affecting the aesthetics and function of the area. The free gingival grafts and atraumatic extractions are conservative procedures thatpromote conservation, healing, aesthetics and maintenance of tissues, thus facilitating its handling during rehabilitation therapy. This is a case report of a left upper lateral incisor which had an atraumatic extraction and subsequent placement of a free gingival graft.

Keywords: TRANSPLANTATION AUTOLOGOUS / GINGIVOPLASTY / TOOTH EXTRACTION / ALVEOLAR PROCESS / WOUND HEALING.

\section{Introducción}

La pérdida dentaria constituye un fenómeno que presenta un impacto negativo sobre la calidad de vida del individuo (1). A pesar de su importancia funcional desde el punto de vista del paciente el reemplazo de dientes perdidos mediante algún aditamento protésico está condicionado a la posición que estos ocupaban en el arco dentario (2). El reemplazo de dientes perdidos en zona estética constituye un reto para el profesional, siendo ideal la preservación de los tejidos blandos y duros para lograr mejores resultados después de la rehabilitación oral (3).

Es bien conocido que el mecanismo de reparación de los alvéolos postextracción conlleva a cambios en la arquitectura de los tejidos debido al proceso de reabsorción y remodelado óseo. A esto se adiciona la pérdida ósea que puede ocurrir durante el procedimiento de exodoncia o incluso previo al mismo por etiología periodontal, endodóntica, traumática o patológica (4).

En 1969, Amler (5) describió el proceso de reparación de los sitios postextración. Durante las primeras 24 horas posteriores a la exodoncia se produce la formación del coágulo sanguíneo y comienza el proceso de hemólisis. Después de 2 a 3 días el coágulo se contrae y es reemplazado por tejido de granulación. Después de tres días se observa el incremento de la densidad de fibroblastos y la proliferación del epitelio desde los márgenes gingivales. El remodelado de los sitios comienza con la presencia de los osteoclastos que promueven la reabsorción ósea. Una semana posterior a la exodoncia los sitios se caracterizan por presentar un epitelio que cubre la herida, tejido conectivo joven, nueva red vascular y formación de tejido osteoide en la porción apical. Un mes después de la exodoncia los sitios se caracterizan por un denso tejido conectivo. Un patrón de hueso trabecular empieza a formarse, siendo el sitio cubierto totalmente por el epitelio. Dos meses después de la exodoncia la formación ósea se completa.

Diversos estudios han reportado la pérdida de las dimensiones de los sitios postexodoncia (6-8). Araujo y Lindhe (8) reportaron que durante los primeros seis meses postexodoncia la reabsorción del proceso alveolar en sentido transversal es de un $35 \pm 15 \%$ en el tercio coronal, en el tercio medio de $14 \pm 11 \%$ y apical de $5 \pm 3 \%$ (9). En otro estudio los mismos autores reportaron que se produce la reabsorción del proceso alveolar en sentido vertical, siendo esta mayor en la tabla ósea vestibular. Después de una semana de la exodoncia se encontró que la cresta ósea vestibular se localizaba en promedio a $0,3 \pm 0,2 \mathrm{~mm}$ coronal a la cresta lingual, mientras que a la octava 
semana la cresta ósea vestibular se localizaba $1,9 \pm 0,2 \mathrm{~mm}$ apical a la lingual.

El proceso de reparación de los sitios postexodoncia afecta principalmente a la pared bucal siendo esta parcial o completamente reabsorbida, en especial de las piezas anteriores, debido a la ausencia de tejido óseo medular en el área más coronal de la tabla vestibular. La ausencia de la pieza dentaria trae como consecuencia un decremento del aporte vascular. Esta pérdida de volumen de tejido óseo afecta en manera negativa el contorno del tejido blando. Después de la reparación de los tejidos blandos se observa una mucosa muy delgada en el centro de los sitios postexodoncia $(9,10)$. Varios métodos como el colgajo desplazado coronal, el colgajo pediculado e incluso el uso de injertos de tejido epitelial han sido descritos para mejorar el estado de los tejidos blandos y lograr un cierre primario en sitios que reciben implantes postexodoncia (11-15).

El injerto gingival libre constituye una técnica de cirugía mucogingival. Las primeras referencias de la técnica se hicieron en los años sesenta. En la actualidad su indicación se limita al recubrimiento radicular de superficies sin compromiso estético, en el tratamiento de la inserción anormal de frenillos y/o músculos y la profundización de vestíbulo, sin embargo diversas referencias proponen la técnica inmediatamente posterior a la exodoncia atraumática para favorecer la preservación de los tejidos (13-15).

Para el éxito del injerto de tejido blando es necesario conocer el proceso de cicatrización y revascularización. Este proceso fue estudiado por Nobuto et al. (16). El proceso comprende tres fases. La fase inicial corresponde a los tres primeros días. En los primeros días una fina capa de exudado está presente entre el injerto y el lecho receptor. Durante este periodo el injerto se nutre a través de una "circulación plasmática" proveniente del lecho receptor, siendo de importancia el íntimo contacto con el mismo. Las capas superficiales del injerto degeneran y se descaman. La fase de revascularización comprende del segundo al onceavo día. Después de 4 a 5 días del proceso curativo se observa la anastomosis entre los vasos sanguíneos del lecho receptor y el injerto de tejido blando. Los días posteriores se caracterizan por la proliferación de una densa red de vasos sanguíneos en el injerto. La reepitelización del injerto ocurre a partir del epitelio del tejido adyacente. La tercera fase denominada como fase de maduración de los tejidos comprende desde el día 11 al 42. El número de vasos sanguíneos se reduce, al catorceavo día el sistema vascular del injerto es normalizado. Así mismo, el epitelio madura en forma gradual con la formación de una capa de queratinizada.

La exodoncia atraumática es un procedimiento que tiene como objetivo la mínima afección de los tejidos duros y blandos alrededor del diente. Constituye un procedimiento en el cual se remueve de manera cuidadosa el diente mediante el uso de periotomos y leves movimientos rotacionales con los fórceps. La complejidad del procedimiento depende de la ubicación del diente y el biotipo del paciente. Los dientes muy vestibularizados o con un biotipo delgado por lo general están particularmente predispuestos a una mayor reabsorción postexodoncia debido al poco grosor de las tablas óseas (17).

El propósito de este trabajo es presentar el uso combinado de la exodoncia atraumática y la técnica de injerto epitelial libre como una alternativa de tratamiento que favorece la conservación, cicatrización, manejo y adaptación de los tejidos con el fin de mejorar la estética y función del sitio postexodoncia.

\section{Reporte de caso}

Se presenta a la consulta un paciente de sexo femenino de 55 años en buen estado general. La paciente se encuentra en fase de tratamiento rehabilitador $\mathrm{y}$ endodóntico (Fig. 1). Es derivada al servicio de Periodoncia e Implantología Oral de la Facultad de Estomatología de la Universidad Peruana Cayetano Heredia. La interconsulta refiere la necesidad de realizar la exodoncia de la pieza 22 , la cual después del retratamiento de conducto no muestra una evolución favorable. Se solicita un manejo conservador que permita mejorar las condiciones de la prótesis parcial fija convencional a ser realizada de manera posterior.

$\mathrm{Al}$ examen clínico la pieza 22 presentaba un espigo colado. Los márgenes gingivales se encontraban eritematosos, edematosos y sangrantes a la evaluación (Fig. 2).

Al examen radiológico se observa en la pieza 22 evidencia una imagen apical radiopaca compatible con tratamiento de conducto e imagen radiopaca de mayor densidad compatible con espigo colado. A nivel periapical se observa una imagen radiolúcida de bordes definidos compatibles con absceso periapical versus granuloma periapícal (Fig. 3).

Se decidió instruir a la paciente 


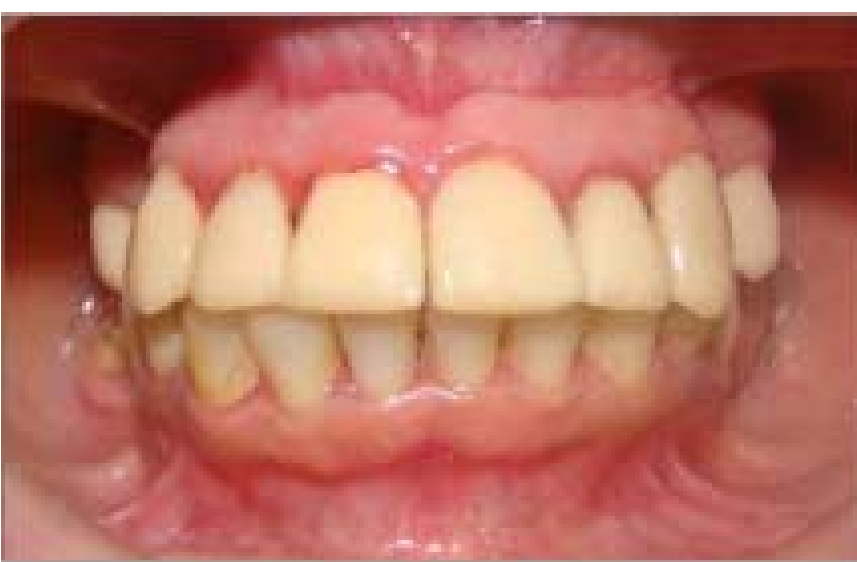

Fig. 1. Vista preoperatoria frontal.

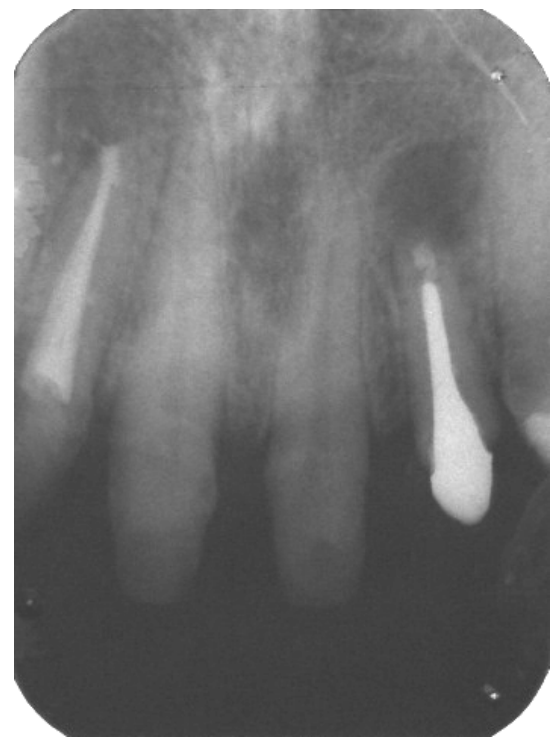

Fig. 3. Radiografía periapical pieza 22.

en medidas de higiene oral, se realizó una profilaxis simple y se precedió a realizar la exodoncia atraumática de la pieza 22. Para ello se usó una hoja de bisturí $\mathrm{N}^{\circ} 11$ con la cual se realizó una incisión hacia el espacio ocupado por el ligamento periodontal en toda la periferie del diente. Luego mediante el uso de un bisturí de Orban se procedió a ampliar el espacio anteriormente ganado, para finalmente mediante un fórcep recto anterior proceder a la luxación de la pieza mediante leves movimientos rotacionales y su avulsión progresiva (Fig. 4).

Luego se procedió a la obtención del injerto gingival libre del reborde edéntulo de las piezas 25 y 26. Para ello mediante el uso de un bisturí favorable (Fig.6).

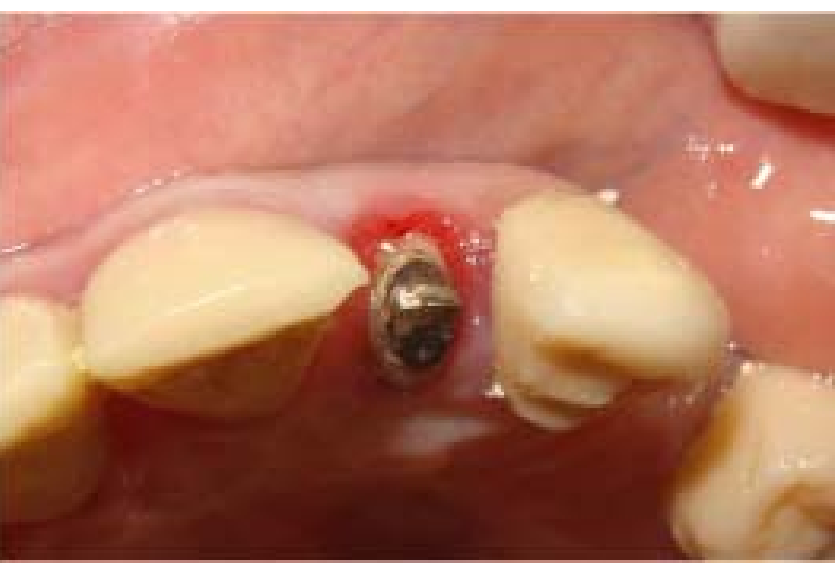

Fig. 2. Vista preoperatoria oclusal.

N 15 se realizó una incisión de 1.2 $\mathrm{x} 0.8 \mathrm{~cm} 2 \mathrm{con} 2 \mathrm{~mm}$ de profundidad. Mediante el bisturí y el uso de una pinza Addson sin uña se procedió a la parcialización del injerto y obtención del mismo.

El injerto fue trasladado al alveolo y se suturó al mismo con seda negra 4/0 mediante la técnica de sutura colchonero horizontal. Se tuvo especial cuidado en que el injerto quedase con la menor movilidad y el mayor contacto con las paredes adyacentes (Fig. 5).

Se indicó como medicación postoperatoria ketarolaco de $10 \mathrm{mg}$ como dosis inicial, siendo esta continuada por ibuprofeno de 400mg cada 8 horas condicionado al dolor.

A los 10 días se realizó en primer control postoperatorio observandose una necrosis superficial del injerto epitelial. La zona donadora evidenciaba un proceso de cicatrización con evoluación

A los 21 días se observó la evolución favorable e integración total del injerto a los tejidos circundantes. Se precedió al retiro de puntos e irrigación de la zona comprometida (Fig. 7).

Finalmente se indicó al servicio de Rehabilitación Oral la planificación de la confección de un póntico ovoide para el manejo y adaptación de tejidos blandos.

\section{Discusión}

El manejo de tejido blando postexodoncia ha sido estudiado por diversos autores. Jung et al. (9) evaluaron 20 sitios reportando que después de una semana postcirugía el $43 \%$ de los injerto está vital, el $31 \%$ parcialmente vital y $26 \%$ no vital. Después de la primera semana el 64,3\% del área del injerto se encuentra integrada, 35,6\% fibrinoide y tan solo $0,1 \%$ aparece necrótica. Después de la tercera semana un 92,3\% del área del injerto se encuentra integrada, un $5,5 \%$ muestra fibrina y un 2,1\% se encuentra necrótica, estando los tejidos preparados para su manipulación. Después de seis semanas el 99,7\% del área se encuentra integrada. Tal et al. (15) evaluaron 40 sitios. Una semana posquirúrgica 18 injertos (43\%) se encontraban vitales, 13 (31\%) parcialmente vitales y 11 (26\%) no vitales, 3 de estos perdidos. A la segunda y tercera semana los resultados fueron similares. Los resultados de los estudios anteriores nos demuestran una importante predictibilidad y éxito del procedimiento.

El éxito de la técnica, también llamada injerto tapa, es comprometido por diferentes factores como son un adecuado 


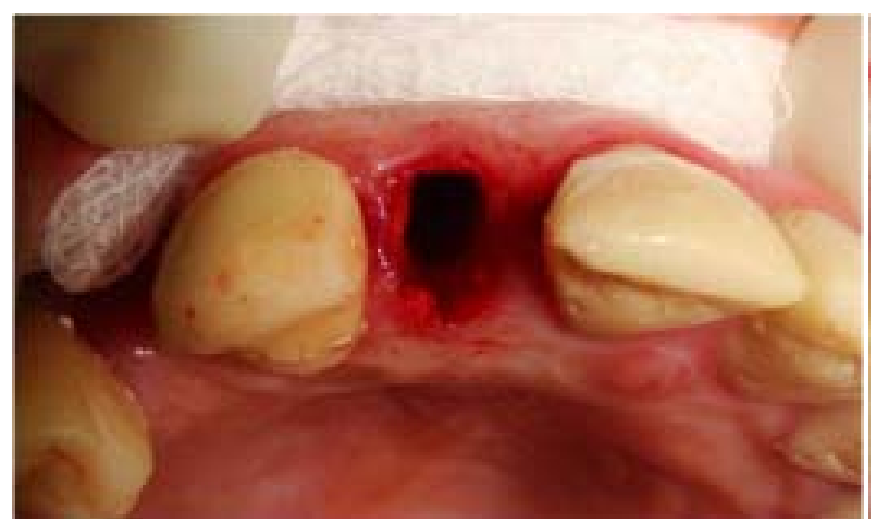

Fig. 4. Alveólo postexodoncia.

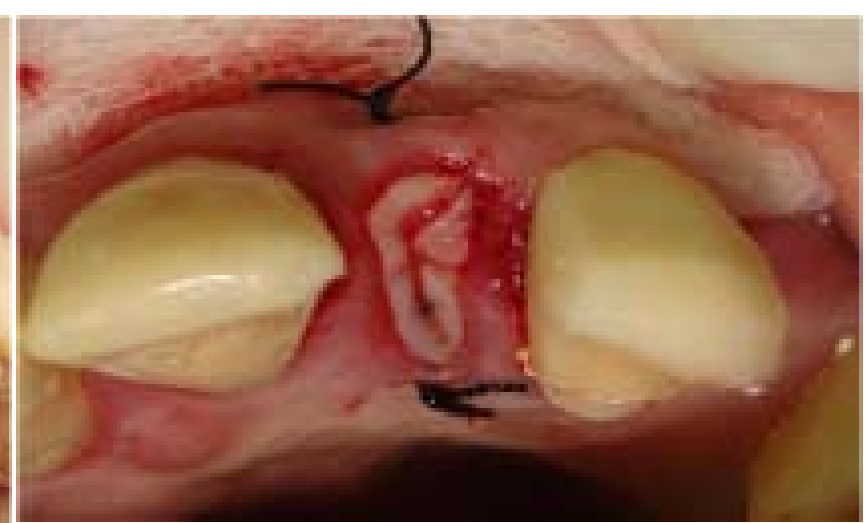

Fig. 5. Injerto epitelial libre suturado.

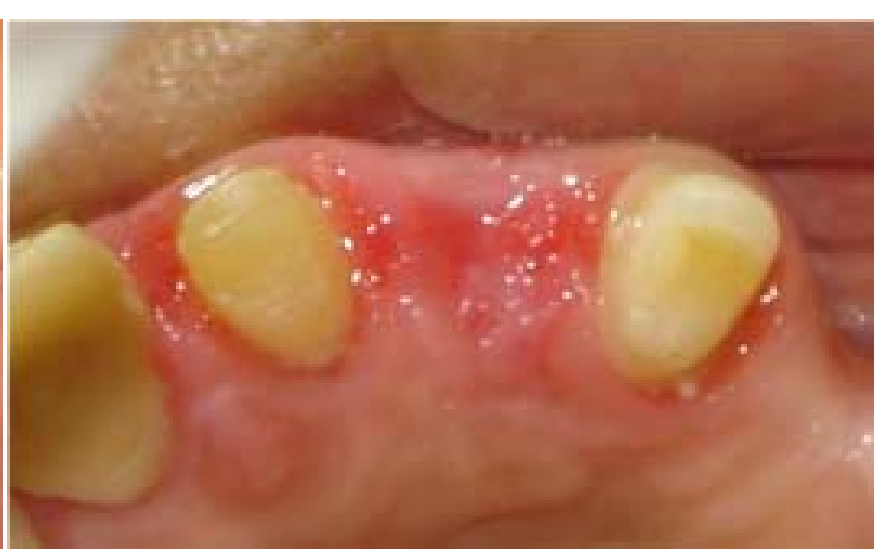

Fig. 7. Control a los 21 días lecho receptor.

Fig. 6. Control a los 10 días lecho donador. soporte sanguíneo proveniente del coágulo $(16,17)$, estabilidad e íntimo contacto del injerto con los tejidos marginales del alvéolo $(10,17)$.Esta técnica no requiere colgajo periodontal lo cual reduce la injuria traumática de los tejidos duros y blandos, optimizando de esta manera la preservación de la topografía del reborde (14). Está indicada cuando no hay pérdida de los tejidos duros ya que en ese caso se debe aplicar otras técnicas para la preservación del alvéolo $(18,19)$.

La desventaja de esta técnica es la necesidad de un segundo sitio quirúrgico para la obtención del injerto de tejido blando. Sin embargo, Landsberg et al (12) citan diferentes ventajas, especialmente en combinación con la colocación de implantes dentales inmediatos. Entre estas ventajas tenemos: Menor contaminación del sitio quirúrgico del implante, no pérdida de encía queratinizada en la zona vestibular, mejor conservación de papila dental y reducción del tiempo de espera entre la exodoncia y colocación del implante.

En el presente trabajo se observó que a los 21 días el injerto de tejido blando se encontró totalmente integrado al tejido blando circundante. Como tratamiento complementario hubiera sido ideal la colocación de un injerto óseo en el alvéolo postexodoncia, ya que constituye una técnica de preservación de reborde con resultados ampliamente conocidos $(7,8,20)$, sin embargo limitaciones económicas del caso no permitieron su empleo.

El reporte de caso presentado junto a los estudios antes mencionados demuestra el éxito del manejo de tejidos, evidencia una posibilidad de tratamiento conservador que favorece la cicatrización, la estética y el mantenimiento estos, facilitando así su manejo durante la terapia rehabilitadora.

\section{Referencias bibliográficas}

1. Mack F, Schwahn C, Feine JS, Mundt T, Bernhardt O, John U, Kocher PT, Biffar R. The impact of tooth loss on general health related to quality of life among elderly Pomeranians: results from the study of health in Pomerania (SHIP-O). Int J Prosthodont. 2005; 18(5):414-9.

2. Elias AC, Sheiham A. The relationship between satisfaction with mouth and number and position of teeth. J Oral Rehabil. 1998; 25(9):649-61.

3. Grunder U. Stability of the mucosal topography around single-tooth implants and adjacent teeth: 1-year results. Int J Periodontics Restorative Dent. 
2000; 20(1):11-7.

4. Schropp L, Wenzel A, Kostopoulos L, Karring T. Bone healing and soft tissue contour changes following single-tooth extraction: a clinical and radiographic 12-month prospective study. Int $\mathrm{J}$ Periodontics Restorative Dent. 2003; 23(4):313-23.

5. Amler MH. The time sequence of tissue regeneration in human extraction wounds. Oral Surg Oral Med Oral Pathol. 1969; 27(3):309-18.

6. Pietrokovski J, Massler M. Alveolar ridge resorption following tooth extraction. J Prosthet Dent. 1967; 17(1):21-7.

7. Araújo MG, Lindhe J. Dimensional ridge alterations following tooth extraction. An experimental study in the dog. $\mathrm{J}$ Clin Periodontol. 2005; 32(2):212-8.

8. Araújo MG, Lindhe J. Ridge alterations following tooth extraction with and without flap elevation: an experimental study in the dog. Clin Oral Implants Res. 2009; 20(6):545-9.

9. Jung RE, Siegenthaler DW, Hämmerle $\mathrm{CH}$. Postextraction tissue management: a soft tissue punch technique. Int $\mathrm{J}$
Periodontics Restorative Dent. 2004; 24(6):545-53.

10.Becker W, Becker BE. Guided tissue regeneration for implants placed into extraction sockets and for implant dehiscences: surgical techniques and case report. Int $\mathrm{J}$ Periodontics Restorative Dent. 1990; 10(5):376-91.

11. Gher ME, Quintero G, Assad D, Monaco E, Richardson AC. Bone grafting and guided bone regeneration for immediate dental implants in humans. J Periodontol. 1994; 65(9):881-91.

12. Bichacho N, Landsberg CJ. A modified surgical/prosthetic approach for an optimal single implant-supported crown. Part II. The cervical contouring concept. Pract Periodontics Aesthet Dent. 1994; 6(4):35-41.

13.Evian CI, Cutler S. Autogenous gingival grafts as epithelial barriers for immediate implants: case reports. J Periodontol. 1994; 65(3):201-10.

14.Landsberg CJ. Socket seal surgery combined with immediate implant placement: a novel approach for single-tooth replacement. Int J Periodontics Restorative Dent. 1997; 17(2):140-9.
15. Tal H. Autogenous masticatory mucosal grafts in extraction socket seal procedures: a comparison between sockets grafted with demineralized freeze-dried bone and deproteinized bovine bone mineral. Clin Oral Implants Res. 1999; 10(4):289-96.

16. Nobuto T, Imai H, Yamaoka A. Microvascularization of the free gingival autograft. J Periodontol. 1988; 59(10):639-46.

17.Dibart S. Karima M. Practical Periodontal Plastic Surgery. Ed. Blackwell Munksgaard. 2006

18. Cortellini P, Bowers GM. Periodontal regeneration of intrabony defects: an evidencebased treatment approach. Int J Periodontics Restorative Dent. 1995; 15(2):128-45.

19. Cortellini P, Carnevale G, Sanz M, Tonetti MS. Treatment of deep and shallow intrabony defects. A multicenter randomized controlled clinical trial. J Clin Periodontol. 1998 Dec;25(12):981-7.

20.Araújo MG, Lindhe J. Ridge preservation with the use of BioOss collagen: A 6-month study in the dog. Clin Oral Implants Res. 2009; 20(5):433-40. 